\title{
Weak Form of Efficiency Hypotheses: Empirical Modeling With Box - Pierce, ADF and ARCH Tests
}

\author{
Saliha Theiri ${ }^{1} \&$ Abdessatar Ati ${ }^{2}$ \\ ${ }^{1}$ University of Tunis El Manar, Tunis, Tunisia \\ ${ }^{2}$ University of Jendouba, Tunisia \\ Correspondence: Saliha Theiri, University of Tunis El Manar, Tunis, Tunisia. E-mail: Saliha_theiri@yahoo.fr
}

Received: June 30, 2020

doi:10.5430/ijfr.v11n5p137

Accepted: September 1, 2020

Online Published: September 21, 2020

URL: https://doi.org/10.5430/ijfr.v11n5p137

\begin{abstract}
The aim of this paper is to analyze the information efficiency after period of revolution. In particularly, it is a question of testing the weak form of efficiency on the Tunisian stock market. Based in many studies in literature of efficiency in developed countries, the select sample is compound of 52 companies over the period 2014-2018. By applying the different test of Unit Root (ADF), Box -Pierce and ARCH for detect the presence or not of Conditional heteroskedasticity. These tests show that the efficiency hypothesis in its weak form is not verified for majority of companies making up our sample, but it is only confirmed in 10 companies.
\end{abstract}

Keywords: random walk, efficiency, emerging market, heteroskedasticity

JEL Classification: G12-G14

\section{Introduction}

Over the past decade, Tunisia has experienced a series of economic reforms aimed at ensuring the country's transition from an economy directed towards a market economy based on a developed and efficient financial market. In addition, despite the efforts made and the development experienced by the Tunisian financial market during this period, both in terms of organization and in terms of the legal framework, the results remain below expectations.

In particular, growth deceleration translates into a drop in investment, generate a lack of confidence to invest in a risky country, where the efficiency of the stock market is questioned. The inefficiency of stock markets has become a real paradigm in research in emerging countries. However, the term of information efficiency was first introduced by Louis Bachelier in 1900. He is interested in bizarre movements upward followed by similar downward fluctuations, which he called martingales. This means an alternative to the random walk model (Samuelson, 1965).

This concept is the origin of the notion of "random walk" of stock prices (Sangare, 2005). However, Fama (1991) considers the efficiency is not directly testable and any efficiency test is a joint test of efficiency hypothesis and a model for evaluating financial assets. Often, in the literature, the informational efficiency of market is illustrated in three forms: strong, semi-strong and weak efficiency (Fama, 1970).

Therefore his study focuses on the low of efficiency of stock markets. This form consists in demonstrating that the current price of a financial asset is entirely, independent of all the information published relatively in the past. This assumes that the investors have analyzed all of this information and have already incorporated it into the prices. In particular, financial analysts can use all this past information from financial assets and the company can follow the evolution of its market. However, for a high level of risk, the observation of prices and volumes of past transactions would be immaterial for an investor wishing to obtain higher profitability of the market. In this case, economic agents cannot take advantage of the past information, to predict the future evolution of price an asset.

This study tests the weak form of efficiency in financial market of Tunisia. This choice is explained by the absence of empirical validation concerning its level of efficiency after the revolution. It is structured as follows: Section 2 presents the literature review. Section 3 outlines the experimental design. Section 4 reports the results and section 5 concludes this research.

\section{Literature Review}

The weak form of informational efficiency has traditionally been verified in the emerging and developed markets. 


\subsection{Studies on Developed Markets}

According to Fama (1965), the weak form of efficiency assumed the unpredictability of stock prices, which suggests that they follow a random Walk. The test of this form realized in first by Poterba and Summers (1986) on the American market. Her study detected the existence of a negative serial correlation of long-term returns. This result is confirmed by Fama and French (1988). The correlation is positive in the short term and it is negative in the long term. The weak form of market is show that an investor cannot anticipate the future prices of security exchange by using the sequence of past prices. The previous prices in market exchanges include the character of random walk. Also, the hypothesis of random walk has been tested by Lo and MacKinlay (1988) in the American market. The results obtained link the absence of randomness for the entire sample and all the sub-periods (608 weeks) for the index returns. In addition, Lee 1992 confirmed the existence of random walk character for weekly serial returns in United States with a study based on the variance test. However, another technique used by Huang (1995) for proved the degree of efficiency in Asian countries during 1988-1992. By applying the statistical variance ratio validated the hypothesis of a random market. In fact, the level of the autocorrelation of series is negligible by checking the hypothesis of independence of successive prices. To better understand this, many researchers have conducted their studies on several markets to test whether the character of the market studied influences the level of efficiency.

Remember that a random walk of stock prices assumes that you cannot predict the future price movement of a share based on its past price. With several methodological contributions, Shaker (2013) tested the weak form of efficiency of European markets, based on daily data. He showed that the price series do not follow a random market, which proves the inefficiency of the markets.

In the same context, to test the weak form of the efficiency hypothesis on the French market, Rivals and Personnaz (2003) showed the value of verifying the independence of successive prices. These authors explain that the serial correlations of successive prices are used to test the weak form of efficiency; the principle of which is to test the variations of independence of successive price. This method makes it impossible to achieve profitability superior to the market in the future, based only on past prices. This interpretation relied in the absence of prediction or betting market in this study. They are based on the approach of Mincer and Zarnowitz (1969).

In the cross-listed securities, the informational efficiency is motivate by the quality of institution and informational efficiency (Benjamin and al, 2018). These two criteria are classified by Clebkin and al (2020) as constraints effects of efficiency. Angelini and De Angelis (2019) extend a previous application, which only applied to test the weak-form efficiency of traditional betting markets. The weak form is modified not only by the content of all the information which includes the history of price series but also, that of all economic or financial variables, such as interest rates and dividend / price ratios, which can help in forecasting.

\subsection{Studies on Emerging and African Markets}

Several works have been carried on emerging and African markets, including the study of Mai and al. (1995) which provides an analysis of predictability of returns on equities on the Jamaican market. From daily data for the period 1989- 1996, these authors have shown strong serial correlations. This explains the predictability of profitability. In particular, $25 \%$ of daily returns can be forecast using the returns from the previous day. The autocorrelation tests thus reject the hypothesis of weak form of efficiency. In addition, the results of the variance ratio tests ensure the rejection of this hypothesis in daily prices at 5\%. Also, this result proved_by Abraham and al. (2002), Omran and Farrar (2006), Mlambo and Biekpe (2007). The weekly indices rejected the hypothesis of a random walk in the stock markets of Middle East during the period 1992 - 1998. This inefficiency in emerging markets is explained by lack of diffusion of information. The historical prices relied to the expense of available information. These prices are outlying from integrating several information, which can cause a spread between prices and reality.

For MENA region, Khazali et al. (2007) based their study on weekly data from October 1994 to December 2003. These authors have shown the inefficiency in its weak sense. They attribute this result to the youth of these markets and the limited number of their transactions. However, after correcting the returns of these indices (statistical bias), the efficiency hypothesis is verified.

Saymeh (2013) shows that the markets of Jordan and Turkey are not efficient in the weak sense during 2002-2012. In particular, the current price of financial asset is dependent on all information published in the past. Also, the Moroccan market for the period from January 01, 2002 to December 31, 2013, is efficient in semi-strong form, because this a young market, the low level of capitalization and the limited number of transactions. Relatively Angelovska (2018) tested the weak form of stock market efficiency in the Macedonian stock exchange. He applied the Random Walk Model and GARCH model on sample spanning from 2005 to 2018. He provides the inefficiency 
of Macedonian Stock. This negative implication of inefficiency can be manifested in the disturbing of the allocation of national resources for development projects.

On the other hand, various authors have attempted to test the efficiency hypothesis by working on longer horizons. Summers (1986) shows that if the usual pattern of stock price formation is proved negative, long-term auto-correlations will appear. This appearance is reflected in the use of average returns (mean reversion). A period of increase (or decrease) will be followed by a decreasing trend (or increasing) returns in order to return to the average values. Lardic and Mignon (2006) explain that the return of prices to their fundamental value suggests that during the period of the "mean reversion" phenomenon returns are predictable from past returns, which moves away from the hypothesis of a random walk of prices which on the other hand, contains a transient stationary component. For the latter, the rejection of random walk does not, however, imply the rejection of hypothesis of the efficiency of financial markets. The presence of "mean reverting" in prices explains the difference in the price of fundamental value shares.

This phenomenon contradicts the hypothesis of Samuelson, which stipulates that prices must be equal at all times to the fundamental value. For Fama and French (1988a), these negative serial correlations can result from the fact that the expected returns vary over time. In the meantime, the "adversaries" of efficiency are based on the presence of a gap between the observed price and the fundamental value of the "mean reversion" phenomenon. The "proponents" of efficiency support this theory by the fact that prices ultimately tend to return to basic value. This process verifies the long-term hypothesis of efficiency and the validity of the financial asset model.

This debate on the predictability of returns from past returns, prompted researchers to study the predictability of these using other economic or financial variables including interest rates, the dividend / price ratio (dividend yield ) and the PER (Battour and Martines, 2019). Its study shows the market efficiency by using laboratory experiments. It utilizes three experimental treatments with two distinguishing dimensions: uncertainty and asymmetric information. These authors show that both uncertainty and information asymmetry affect the level of market efficiency (Battour and Martines, 2019).

\section{Empirical Validation}

\subsection{Objectives and Hypotheses of the Study}

Our study attempts to reinforce recent studies on the weak form of efficiency in emerging markets. These markets differ from developed markets in terms of size, liquidity and trading volume etc. It is based on the following question: is the hypothesis of efficiency in its weak form verified in the Tunisian stock market? This question is divided into two sub-hypotheses:

H0: The Tunisian stock market follows a random walk.

H1: The Tunisian stock market does not follow a random walk.

To validate these hypotheses, we carry out various tests verifying the independence of successive variations in stock market prices. These tests are the subject matter in the following paragraph.

\subsection{Methodology Used}

We start from the definition of efficiency in the weak sense, which stipulates that it is impossible to predict the future returns of stocks based on past returns. Many tests have been used in previous studies, including those of random walk and autocorrelation. Specifically, the tests used on efficiency in its weak form, consist in calculating the coefficients of auto-correlation or auto-covariance, and make the random walk test in order to study the hypothesis of the existence of a price series memory. Specifically, to test the efficiency in its weak form of the Tunisian stock market and increase the relevance of our results, we have chosen to diversify our tests by opting for the 3 most efficient ones in the literature as: Unit Root (ADF), Box -Pierce, and ARCH. The objective of using these tests is to detect the presence or not of conditional heteroskedasticity in our price series. These tests make it possible to assess the autocorrelated character of the returns and to analyze the random character of our price series.

If the market is efficient in the weak sense, the autocorrelation coefficients must be near to 0 or not significantly different from 0 . A detailed presentation of these different tests will be explained later.

We are interested in the profitability series of stock prices, since investors are more interested in the evolution of profitability in that of stock prices (raw evolution). The profitability series will be calculated from the transformation of the series of stock prices into logarithms, $\mathrm{R}_{(\mathrm{t})}=\ln \left(\mathrm{P}_{(\mathrm{t})} / \mathrm{P}_{(\mathrm{t}-1)}\right)$, as an approximation of the rate of return.

With: 
- $\quad \mathrm{R}(\mathrm{t})$ and $\mathrm{P}(\mathrm{t})$ respectively represent the return on the action and the share price on date $\mathrm{t}$.

- The average of the last $n$ values of $\mathrm{R}(\mathrm{t})$ is $\overline{\mathrm{R}}=\frac{1}{3} \sum_{\mathrm{k}=1}^{\mathrm{N}} \mathrm{R}_{\mathrm{t}-\mathrm{k}+1}$

- The standard deviation is obtained by $\sigma^{2}=\frac{1}{3} \sum_{\mathrm{k}=1}^{\mathrm{N}} \quad\left(\mathrm{R}_{\mathrm{t}-\mathrm{k}+1}-\overline{\mathrm{R}}^{2}\right.$

\subsection{Data Collection Method}

Our data is collected from the site of the Tunis Stock Exchange. They concern the daily stock market prices of 52 Tunisian companies listed on the BVMT, of which we are testing the predictability of stock market prices. The study period covers 4 years, from January 04, 2014, to 31 December 31, 2018.Thus, we want to show the impact of the Tunisian revolution on the efficiency of the stock market. It should be noted that the number of trading days differs from one company to another.

\section{Results and Discussion}

\subsection{Descriptive Statistics}

A series of returns, which follows a standard normal distribution, indicates that the distribution of returns around the average is symmetrical.

To apply the normality tests on our profitability series, we will calculate the coefficients of symmetry "skewness" and statistic "Kurtosis" to determine the symmetrical character or not of a distribution. For the distribution of our series of profitability to be symmetrical (follows a standard normal distribution), the coefficients of Skewness and Kurtosis must be close to 0 and 3, respectively, in the normal case. To do this, we propose to use the Jarque-Bera test (1982, 1987), which is interested in the indicators of the form of the distribution based on the coefficients of skewness and kurtosis. The descriptive statistics of the return series of the 52 companies making up our sample are summarized in Table 1:

Table 1. Descriptive statistics

\begin{tabular}{lllllllr}
\hline Financial securities & Max & Min & Std. Dev. & Skewness & Kurtosis & Jarque-Bera & Obs \\
\hline ADW & 0.09504 & -0.19780 & 0.018601 & -1.487365 & 23.07340 & 21069.94 & 1228 \\
\hline AIRL & 0.07356 & -0.14352 & 0.018782 & -1.027305 & 10.87136 & 2429.349 & 881 \\
\hline ALK & 0.13122 & -0.22954 & 0.029645 & -1.138901 & 14.48448 & 2678.805 & 469 \\
\hline AMENB & 0.06686 & -0.65104 & 0.024067 & -15.97571 & 434.7109 & 96196.19 & 1232 \\
\hline AMS & 0.18825 & -0.52518 & 0.035650 & -3.760811 & 62.79203 & 11893.9 & 786 \\
\hline ARTES & 0.13067 & -0.20022 & 0.017361 & -1.594795 & 26.68830 & 29041.54 & 1220 \\
\hline ASSAD & 0.07321 & -0.21222 & 0.014765 & -0.088602 & 8.023589 & 1289.713 & 1225 \\
\hline ASTREE & 0.11917 & -0.10693 & 0.023352 & -0.300510 & 6.577866 & 2067.585 & 377 \\
\hline ATB & 0.08806 & -0.14247 & 0.016012 & -0.202341 & 12.79109 & 4853.481 & 1213 \\
\hline ATL & 0.09531 & -0.16007 & 0.021212 & -0.148345 & 7.625651 & 1061.701 & 1186 \\
\hline ATTIJB & 0.08975 & -0.08752 & 0.014967 & 0.288632 & 9.371863 & 2099.567 & 1231 \\
\hline ATTIJL & 0.13158 & -0.09006 & 0.025638 & 0.612878 & 5.306413 & 254.9729 & 897 \\
\hline BH & 0.12649 & -0.04002 & 0.008252 & 0.636275 & 9.690540 & 2007.985 & 1039 \\
\hline BIAT & 0.08565 & -0.07729 & 0.015991 & 0.014680 & 6.601945 & 647.1215 & 1197 \\
\hline BNA & 0.11528 & -0.10553 & 0.020142 & 0.529857 & 8.331572 & 1173.328 & 953 \\
\hline BT & 0.10032 & -2.26413 & 0.066876 & -31.79302 & 1073.871 & 5859.53 & 1222 \\
\hline BTE & 0.12405 & -0.09884 & 0.013159 & 0.137896 & 18.58723 & 9255.690 & 914 \\
\hline CIL & 0.16014 & -0.31427 & 0.021227 & -3.292986 & 56.09694 & 14038.96 & 1177 \\
\hline CIMEN & 0.14173 & -0.14479 & 0.020189 & 0.335402 & 10.06557 & 2413.66 & 1150 \\
\hline
\end{tabular}




\begin{tabular}{|c|c|c|c|c|c|c|c|}
\hline ELBENE & 0.15415 & -0.14801 & 0.031620 & -0.064043 & 5.075414 & 116.7412 & 648 \\
\hline El-WIFL & 0.08939 & -0.08535 & 0.019778 & 0.370644 & 4.839412 & 194.5168 & 1187 \\
\hline ELEC & 0.16182 & -0.11189 & 0.031460 & 0.616754 & 5.163530 & 288.9287 & 1118 \\
\hline ESSO & 0.10230 & -0.33220 & 0.024585 & -2.237593 & 37.00569 & 55193.42 & 1126 \\
\hline GIFFI & 0.25524 & -0.24784 & 0.030959 & 0.172315 & 12.83743 & 4852.766 & 1202 \\
\hline ICF & 0.16144 & -0.60977 & 0.034179 & -9.226446 & 172.4503 & 720294.7 & 595 \\
\hline MG & 0.11137 & -1.55830 & 0.052342 & -25.18731 & 750.7993 & 24459.157 & 1045 \\
\hline MONO & 0.12395 & -1.58149 & 0.049931 & -26.26868 & 821.8102 & 34389.826 & 1226 \\
\hline POULI & 0.08855 & -0.11967 & 0.016391 & -0.130110 & 7.634658 & 1097.141 & 1222 \\
\hline SERVI & 0.11370 & -0.10650 & 0.024238 & 0.195840 & 5.288875 & 258.1594 & 1149 \\
\hline SFBT & 0.10736 & -0.11889 & 0.015571 & -0.352227 & 14.52567 & 6811.320 & 1226 \\
\hline SIAME & 0.11430 & -0.09292 & 0.021468 & 0.498019 & 6.013087 & 509.4139 & 1214 \\
\hline SICAF & 0.10267 & -0.06067 & 0.025829 & 0.334091 & 3.150134 & 4.572828 & 234 \\
\hline SIMPAR & 0.16138 & -0.15494 & 0.022473 & 0.233229 & 9.788480 & 2133.707 & 1106 \\
\hline SIPHAT & 0.11534 & -0.16714 & 0.026887 & -0.052047 & 5.986883 & 285.4615 & 767 \\
\hline SITS & 0.11300 & -0.09560 & 0.021043 & 0.308089 & 5.496910 & 338.4283 & 1228 \\
\hline SOMO & 0.15882 & -0.11614 & 0.025297 & 0.745978 & 6.319289 & 667.1471 & 1209 \\
\hline SOPAT & 0.18508 & -1.60019 & 0.054489 & -21.57507 & 637.3379 & 19622797 & 1165 \\
\hline SOTE & 0.11826 & -0.66819 & 0.031769 & -7.410898 & 162.0169 & 1295495 & 1219 \\
\hline SOTRA & 0.13154 & -0.08710 & 0.024382 & 0.508774 & 5.593089 & 384.4193 & 1189 \\
\hline SOT & 0.14343 & -0.32499 & 0.024297 & -1.431129 & 34.23367 & 47383.21 & 1150 \\
\hline SOTU & 0.12867 & -2.30238 & 0.069657 & -29.40004 & 970.5368 & 48036.275 & 1227 \\
\hline SPDITS & 0.06859 & -0.10378 & 0.016519 & -0.621050 & 7.249572 & 857.5733 & 1050 \\
\hline STAR & 0.08349 & -0.12253 & 0.018389 & 0.135577 & 6.518244 & 585.7423 & 1129 \\
\hline STB & 0.11707 & -0.09046 & 0.020710 & 0.412292 & 6.498630 & 626.2043 & 1163 \\
\hline STEQ & 0.30295 & -0.25659 & 0.050886 & -0.166588 & 12.44340 & 1339.333 & 360 \\
\hline STIP & 0.32096 & -0.36158 & 0.050532 & -0.336819 & 17.99252 & 4326.285 & 461 \\
\hline TPR & 0.07896 & -0.14497 & 0.016026 & -0.372897 & 12.39580 & 4567.718 & 1234 \\
\hline TUNIN & 0.24048 & -0.20846 & 0.028766 & 0.482958 & 16.08921 & 4363.932 & 608 \\
\hline TUNIS & 0.09194 & -0.10638 & 0.019917 & 0.323161 & 6.458259 & 628.1473 & 1218 \\
\hline TUNLL & 0.08754 & -0.08139 & 0.018849 & 0.084067 & 4.697681 & 138.7286 & 1144 \\
\hline UBCI & 0.13103 & -0.43578 & 0.026796 & -4.980863 & 85.39305 & 250832.5 & 874 \\
\hline UIB & 0.09163 & -0.15597 & 0.016859 & -0.618630 & 16.59872 & 9517.025 & 1225 \\
\hline
\end{tabular}

We can notice that the value of the Kurtosis test is significantly different from 3 whatever the stock price selected. Skewness statistic is also different from 0 . These two statistics are different, then, from the coefficients of a normal distribution. Because of these two remarks and as illustrated by the Jarque-Bera statistics, we can reject the null hypothesis of normality of the profitability series for the entire sample except for the company SICAF. The coefficients of Skewness are different from 0 , which means the presence of an asymmetry phenomenon in the event of a negative or positive event. This asymmetry can result in the presence of non-linearity in the process of profitability evolution, which has proven to be a common feature of financial series.

The results of Kurtosis are very much higher than 3, which translates a high probability of extreme points, proving that the distribution tails are much thicker than those of the normal distribution. 


\subsection{Empirical Results}

4.2.1 Test Unit Root or the Augmented Dickey Fuller (ADF)

To test the stationarity of profitability series, we propose to apply this test whose null hypothesis is the non-stationarity of the time series. The existence of a unit root verifies the non-stationarity of the price series, which follows a random walk. Table 2 presents the results of ADF test after having tested the three models (M1, M2 and M3), which we have retained the most appropriate (the most significant at the threshold of 5\%).

Table 2. Test ADF

\begin{tabular}{|c|c|c|}
\hline Financial securities & Models (Note 1) & Stat ADF \\
\hline ADW & M1 & -37.41206 \\
\hline AIRL & M1 & -30.69808 \\
\hline ALK & M1 & -21.86951 \\
\hline AMENB & M1 & -35.35030 \\
\hline AMS & M3 & -28.51608 \\
\hline ARTES & M1 & -27.82737 \\
\hline ASSAD & M1 & -39.94475 \\
\hline ASTREE & M1 & -21.59226 \\
\hline ATB & M1 & -41.35669 \\
\hline ATL & M1 & -39.88490 \\
\hline ATTIJB & M1 & -36.48578 \\
\hline ATTIJL & M1 & -30.10862 \\
\hline $\mathrm{BH}$ & M2 & -39.60471 \\
\hline BIAT & M1 & -28.70421 \\
\hline BNA & M1 & -33.36192 \\
\hline BT & M1 & -34.83460 \\
\hline BTE & M1 & -23.35274 \\
\hline CIL & M1 & -40.69873 \\
\hline CIMEN & M1 & -38.92662 \\
\hline ELBENE & M1 & -28.06633 \\
\hline El-WIFL & M1 & -28.76062 \\
\hline ELEC & M1 & -33.85053 \\
\hline ESSO & M1 & -34.31768 \\
\hline GIFFI & M1 & -34.76347 \\
\hline ICF & M1 & -22.65793 \\
\hline MG & M1 & -32.55906 \\
\hline MONO & M1 & -35.93303 \\
\hline POULI & M1 & -24.19012 \\
\hline SERVI & M3 & -34.79604 \\
\hline SFBT & M1 & -37.93177 \\
\hline SIAME & M1 & -42.39718 \\
\hline SICAF & M1 & -14.00191 \\
\hline SIMPAR & M1 & -35.60188 \\
\hline SIPHAT & M1 & -29.08808 \\
\hline SITS & M1 & -24.66727 \\
\hline SOMO & M1 & -26.93033 \\
\hline
\end{tabular}




\begin{tabular}{lll}
\hline SOPAT & M1 & -34.01292 \\
\hline SOTE & M1 & -38.35408 \\
\hline SOTRA & M1 & -40.23708 \\
\hline SOT & M1 & -21.32889 \\
\hline SOTU & M1 & -35.29158 \\
\hline SPDITS & M1 & -36.59169 \\
\hline STAR & M1 & -39.81422 \\
\hline STB & M1 & -36.89951 \\
\hline STEQ & M1 & -18.04038 \\
\hline STIP & M1 & -18.23545 \\
\hline TPR & M1 & -38.47839 \\
\hline TUNIN & M1 & -27.81892 \\
\hline TUNIS & M1 & -23.55392 \\
\hline TUNLL & M1 & -43.63714 \\
\hline UBCI & M1 & -30.28279 \\
\hline UIB & M1 & -40.10031 \\
\hline
\end{tabular}

The ADF stat is the value of $t$ statistic DF. It consists of comparing the critical values -1.95 for model $1,-2.86$ for model 2 and -3.41 for model 3 at the threshold of $5 \%$. Then, at the threshold of $1 \%$ to compare -2.58 for model 1 , -3.43 for the Model 2 and -3.96 for model 3. And finally, at the threshold of 10\%,-1.61 for model 1,-2.56 for model 2 and -3.12 for model 3. We note that the various statistics of Dickey-Fuller and t-statistic, are always lower than the critical values. The null hypothesis of the existence of a unit root is therefore, rejected at the threshold of $1 \%, 5 \%$ and $10 \%$, for any stock price studied. In other words, the profitability series are all stationary (stable) and therefore predictable. The random walk hypothesis is therefore, rejected.

\subsubsection{Serial Correlation Test}

In order, to found the presence of heteroskedasticity in the data, the test of $\mathrm{ARCH}$ and Box-Pierce detect the presence of serial correlation or not.

\section{i/ Test ARCH «Auto Regressive Conditional Heteroscedasticity»}

Test ARCH is introduced by Engle (1982). It allows checking whether the conditional variance is independent of time and has for the null hypothesis, the absence of effect ARCH. However, the presence of the ARCH effect shows the heteroscedastic nature in profitability series. The results of this test are summarized in Table 3:

Table 3. Test ARCH (Note 2)

\begin{tabular}{lllll}
\hline & Q & TR $^{\mathbf{2}}$ & $\begin{array}{l}\text { Probabili } \\
\text { ty }\end{array}$ & Decisions \\
\hline ADW & 1 & 2.472959 & 0.1158 & The null hypothesis is accepted \\
\hline AIRL & 2 & 49.23504 & 0.0000 & The null hypothesis is rejected \\
\hline ALK & 1 & 2.802029 & 0.0941 & The null hypothesis is accepted \\
\hline AMENB & 2 & 0.028941 & 0.8729 & The null hypothesis is accepted \\
\hline AMS & 1 & $7.11 \mathrm{E}-06$ & 0.9979 & The null hypothesis is accepted \\
\hline ARTES & 1 & 1.214111 & 0.2705 & The null hypothesis is accepted \\
\hline ASSAD & $\mathbf{3}$ & 44.46024 & 0.0000 & The null hypothesis is rejected \\
\hline ASTREE & 1 & 0.696620 & 0.4039 & The null hypothesis is accepted \\
\hline ATB & $\mathbf{1}$ & 79.96012 & 0.0000 & The null hypothesis is rejected \\
\hline ATL & $\mathbf{2}$ & 35.17359 & 0.0000 & The null hypothesis is rejected \\
\hline ATTIJB & $\mathbf{3}$ & 145.6888 & 0.0000 & The null hypothesis is rejected \\
\hline
\end{tabular}




\begin{tabular}{|c|c|c|c|c|}
\hline ATTIJL & 2 & 15.54662 & 0.0004 & The null hypothesis is rejected \\
\hline $\mathrm{BH}$ & 1 & 75.96641 & 0.0000 & The null hypothesis is rejected \\
\hline BIAT & 3 & 137.4515 & 0.0000 & The null hypothesis is rejected \\
\hline BNA & 3 & 48.56345 & 0.0000 & The null hypothesis is rejected \\
\hline BT & 1 & 0.000979 & 0.9750 & The null hypothesis is accepted \\
\hline BTE & 1 & 5.413621 & 0.0200 & The null hypothesis is rejected \\
\hline CIL & 1 & 0.179427 & 0.6719 & The null hypothesis is accepted \\
\hline CIMEN & 3 & 156.1037 & 0.0000 & The null hypothesis is rejected \\
\hline ELBENE & 1 & 32.62984 & 0.0000 & The null hypothesis is rejected \\
\hline El-WIFL & 1 & 78.66202 & 0.0000 & The null hypothesis is rejected \\
\hline ELEC & 1 & 56.98960 & 0.0000 & The null hypothesis is rejected \\
\hline ESSO & 1 & 0.183368 & 0.6685 & The null hypothesis is accepted \\
\hline GIFFI & 1 & 43.07196 & 0.0000 & The null hypothesis is rejected \\
\hline ICF & 1 & 0.018661 & 0.8913 & The null hypothesis is accepted \\
\hline MG & 1 & 0.000888 & 0.9762 & The null hypothesis is accepted \\
\hline MONO & 1 & 0.000723 & 0.9785 & The null hypothesis is accepted \\
\hline POULI & 1 & 226.3653 & 0.0000 & The null hypothesis is rejected \\
\hline SERVI & 3 & 76.15591 & 0.0000 & The null hypothesis is rejected \\
\hline SFBT & 2 & 76.21780 & 0.0000 & The null hypothesis is rejected \\
\hline SIAME & 2 & 40.10037 & 0.0000 & The null hypothesis is rejected \\
\hline SICAF & 1 & 5.880335 & 0.0153 & The null hypothesis is rejected \\
\hline SIMPAR & 1 & 28.72280 & 0.0000 & The null hypothesis is rejected \\
\hline SIPHAT & 1 & 53.93971 & 0.0000 & The null hypothesis is rejected \\
\hline SITS & 1 & 23.57038 & 0.0000 & The null hypothesis is rejected \\
\hline SOMO & 4 & 91.81414 & 0.0000 & The null hypothesis is rejected \\
\hline SOPAT & 1 & 0.001858 & 0.9656 & The null hypothesis is accepted \\
\hline SOTE & 1 & 0.010391 & 0.9188 & The null hypothesis is accepted \\
\hline SOTRA & 3 & 77.45043 & 0.0000 & The null hypothesis is rejected \\
\hline SOT & 1 & 4.558171 & 0.0328 & The null hypothesis is rejected \\
\hline SOTU & 1 & 0.001179 & 0.9726 & The null hypothesis is accepted \\
\hline SPDITS & 3 & 50.98271 & 0.0000 & The null hypothesis is rejected \\
\hline STAR & 3 & 76.03832 & 0.0000 & The null hypothesis is rejected \\
\hline STB & 3 & 74.42816 & 0.0000 & The null hypothesis is rejected \\
\hline STEQ & 1 & 2.074723 & 0.1498 & The null hypothesis is accepted \\
\hline STIP & 1 & 25.45280 & 0.0000 & The null hypothesis is rejected \\
\hline TPR & 1 & 11.48332 & 0.0007 & The null hypothesis is rejected \\
\hline TUNIN & 1 & 1.024496 & 0.3115 & The null hypothesis is accepted \\
\hline TUNIS & 3 & 118.2672 & 0.0000 & The null hypothesis is rejected \\
\hline TUNLL & 3 & 43.93121 & 0.0000 & The null hypothesis is rejected \\
\hline UBCI & 1 & 0.041539 & 0.8385 & The null hypothesis is accepted \\
\hline UIB & 1 & 16.69716 & 0.0000 & The null hypothesis is rejected \\
\hline
\end{tabular}

Recall that, the existence of the ARCH effect is defined by the dependence of the conditional variance over time. The results of this test show us that only the series of stock prices in bold (34 series of returns) reject the null hypothesis. This rejection means the presence of ARCH effect and the series are heteroscedastic.

The conditional variances of these different series are, therefore time-dependent, which presupposes the 
predictability of the risk. Future volatility (standard deviation) is predictable from its past value. The condition of white noise is not respected. Thus, the existence of an $\mathrm{ARCH}$ effect in these price series is contrary to the random walk hypothesis.

For the other remaining series of profitability, the null hypothesis is accepted, which shows the absence of an ARCH effect. However, we remain cautious about accepting the random walk hypothesis for this profitability series. Thus, these interpretations require the Box-Pierce test, which is sensitive to the presence of heteroskedasticity.

\section{ii- Test de Box-Pierce}

The test of Box-Pierce is a simplified version of test of Ljung - Box. This detects the presence of serial correlation in the price series.The values of Autocorrelation coefficients have zero or significantly different from zero, which implies that the market is efficient in the weak sense. It calculates the autocorrelation $\mathrm{K}$ of the first orders.

In the absence of correlation, the null hypothesis of the absence of autocorrelation is accepted. Therefore, the Box Pierce statistic follows a Chi-Square distribution with a q degree of freedom and shows the number of delays. On the other hand, the presence of serial correlation in the profitability series rejects the null hypothesis and questions efficiency in the weak sense of the market. The results of this test are summarized as follows (Table 4):

Table 4. Test de Box -Pierce (Note 3)

\begin{tabular}{|c|c|c|c|c|c|c|c|c|c|c|c|c|}
\hline $\mathrm{Q}$ & 1 & 2 & 3 & 4 & 5 & 6 & 7 & 8 & 9 & 10 & 11 & 12 \\
\hline $\mathrm{ADW} * * *$ & 5.260 & 5.369 & 8.349 & 9.914 & 13.48 & 14.31 & 14.46 & 14.43 & 14.50 & 14.49 & 15.63 & 15.64 \\
\hline ALK** & 1.428 & 1.969 & 2.679 & 3.879 & 4.605 & 5.805 & 7.216 & 7.227 & 8.332 & 10.47 & 11.53 & 12.89 \\
\hline AIRL & 1.273 & 2.863 & 3.052 & 5.036 & 12.68 & 12.95 & 14.48 & 17.41 & 19.65 & 20.13 & 20.20 & 21.06 \\
\hline AMEB** & 0.089 & 1.886 & 2.823 & 2.824 & 2.900 & 3.379 & 3.393 & 3.486 & 3.487 & 4.622 & 6.081 & 11.09 \\
\hline AMS $^{* *}$ & 0.113 & 1.799 & 2.617 & 2.845 & 2.846 & 2.957 & 4.877 & 7.172 & 7.523 & 7.556 & 9.922 & 10.03 \\
\hline ARTES**** & 11.05 & 16.43 & 16.44 & 16.86 & 20.07 & 25.17 & 25.49 & 25.52 & 25.64 & 26.94 & 28.71 & 28.80 \\
\hline ASSAD $* * * *$ & 21.67 & 21.68 & 21.76 & 25.17 & 25.19 & 31.67 & 34.14 & 35.19 & 35.53 & 37.78 & 38.19 & 39.30 \\
\hline ASTRE*** & 4.277 & 9.191 & 9.292 & 9.299 & 9.910 & 11.19 & 11.33 & 12.14 & 12.17 & 14.48 & 15.36 & 17.44 \\
\hline ATB*** & 36.04 & 36.16 & 44.16 & 44.17 & 44.36 & 45.49 & 46.40 & 46.40 & 46.52 & 47.90 & 48.04 & 48.05 \\
\hline ATL $* * *$ & 25.95 & 25.95 & 26.15 & 26.22 & 26.82 & 32.14 & 32.17 & 32.44 & 32.94 & 33.87 & 33.97 & 35.16 \\
\hline ATJARB & 1.985 & 2.227 & 7.209 & 11.73 & 13.57 & 14.51 & 16.01 & 18.83 & 18.84 & 19.31 & 20.01 & 20.51 \\
\hline ATJARL ** & 0.084 & 0.544 & 0.861 & 0.867 & 0.868 & 7.916 & 9.709 & 9.731 & 9.769 & 11.77 & 12.41 & 12.42 \\
\hline $\mathrm{BH}^{* * * *}$ & 43.57 & 46.69 & 46.70 & 50.98 & 54.84 & 55.44 & 57.20 & 57.72 & 58.56 & 58.74 & 59.88 & 59.92 \\
\hline BIAT $* * *^{* *}$ & 17.61 & 24.42 & 26.27 & 33.09 & 33.79 & 34.45 & 37.71 & 37.71 & 39.37 & 41.08 & 41.09 & 41.09 \\
\hline BNA*** & 5.986 & 5.986 & 6.012 & 6.328 & 13.27 & 14.23 & 14.30 & 14.61 & 14.97 & 17.11 & 17.12 & 17.48 \\
\hline $\mathrm{BT}^{* * *}$ & 0.004 & 0.006 & 0.010 & 0.038 & 0.226 & 0.241 & 0.430 & 0.433 & 0.440 & 0.442 & 0.442 & 0.443 \\
\hline BTE*** & 91.65 & 91.68 & 98.37 & 99.64 & 100.0 & 101.6 & 102.2 & 103.4 & 103.8 & 103.8 & 104.0 & 105.8 \\
\hline $\mathrm{CIL}^{* * *}$ & 34.68 & 34.80 & 34.81 & 34.83 & 35.02 & 40.46 & 40.54 & 40.62 & 40.62 & 41.22 & 41.71 & 42.38 \\
\hline CIMNB $* * *$ & 21.97 & 22.56 & 22.60 & 27.08 & 28.28 & 31.47 & 33.48 & 33.97 & 34.75 & 37.61 & 37.64 & 37.82 \\
\hline EWL $* * *$ & 64.33 & 64.37 & 64.73 & 66.48 & 66.60 & 66.61 & 66.61 & 69.66 & 69.67 & 70.62 & 70.82 & 70.82 \\
\hline ELEC & 0.184 & 3.227 & 6.818 & 14.62 & 15.54 & 23.14 & 23.16 & 32.58 & 36.73 & 39.39 & 41.97 & 42.74 \\
\hline ESSO $* *$ & 0.664 & 0.728 & 0.728 & 0.985 & 1.027 & 1.767 & 2.242 & 3.112 & 3.479 & 3.506 & 3.527 & 4.841 \\
\hline GIFFI & 0.020 & 0.154 & 1.946 & 2.864 & 3.409 & 4.149 & 6.121 & 9.620 & 18.64 & 20.84 & 21.36 & 21.39 \\
\hline $\mathrm{ICF}$ & 3.1158 & 4.1558 & 4.6648 & 4.6756 & 5.2797 & 11.417 & 18.85 & 21.978 & 22.432 & 24.087 & 24.283 & 24.455 \\
\hline MG** & 0.081 & 0.562 & 0.692 & 0.880 & 0.884 & 1.300 & 1.305 & 1.562 & 1.569 & 1.736 & 1.812 & 1.813 \\
\hline MONO** & 1.106 & 1.480 & 1.726 & 2.517 & 2.576 & 2.640 & 3.804 & 3.875 & 4.290 & 4.324 & 4.598 & 4.612 \\
\hline PLTUS** & 1.642 & 5.915 & 6.076 & 6.112 & 9.747 & 9.813 & 13.26 & 15.21 & 15.38 & 15.43 & 15.98 & 17.9 \\
\hline POLIN*** & 25.06 & 27.43 & 35.23 & 35.58 & 37.21 & 38.30 & 43.46 & 43.47 & 43.83 & 45.90 & 47.79 & 49.09 \\
\hline SEVC ** & 0.573 & 0.874 & 0.888 & 4.657 & 4.876 & 7.655 & 8.525 & 11.53 & 11.54 & 11.97 & 11.97 & 11.99 \\
\hline
\end{tabular}




\begin{tabular}{|c|c|c|c|c|c|c|c|c|c|c|c|c|}
\hline SFBT $* * *$ & 6.355 & 6.607 & 12.39 & 12.39 & 12.79 & 12.84 & 13.44 & 13.68 & 16.22 & 16.61 & 16.71 & 16.73 \\
\hline SIAME*** & 46.47 & 46.98 & 46.99 & 47.00 & 53.48 & 54.07 & 54.15 & 54.75 & 55.08 & 55.39 & 55.55 & 57.55 \\
\hline SIMPA $^{* * *}$ & 5.403 & 8.782 & 8.782 & 10.97 & 10.98 & 12.48 & 14.73 & 16.39 & 16.65 & 18.22 & 21.88 & 22.29 \\
\hline SIPHAT & 2.061 & 2.479 & 2.972 & 4.095 & 4.944 & 5.042 & 5.052 & 5.487 & 18.17 & 19.54 & 20.12 & 21.62 \\
\hline SITS**** & 25.92 & 36.09 & 39.92 & 40.84 & 41.62 & 43.47 & 48.23 & 48.36 & 49.56 & 51.18 & 51.93 & 54.98 \\
\hline SOCER & 0.470 & 7.841 & 8.238 & 8.731 & 9.235 & 9.292 & 9.440 & 13.58 & 16.91 & 17.06 & 17.14 & 17.64 \\
\hline SOPAT $* *$ & 0.003 & 0.969 & 1.594 & 2.031 & 2.036 & 2.306 & 3.796 & 3.943 & 4.152 & 4.728 & 5.520 & 5.666 \\
\hline STEL*** & 11.27 & 15.22 & 15.25 & 18.83 & 18.87 & 19.26 & 19.28 & 23.45 & 31.60 & 31.93 & 32.56 & 33.05 \\
\hline STRAP*** & 28.15 & 28.18 & 30.21 & 32.93 & 34.59 & 35.11 & 36.09 & 36.11 & 36.18 & 39.66 & 39.75 & 40.85 \\
\hline SOTUMA & 0.000 & 15.75 & 15.93 & 16.82 & 16.86 & 17.57 & 21.37 & 22.93 & 24.55 & 27.58 & 29.02 & 31.08 \\
\hline SOTUV** & 0.106 & 0.353 & 0.558 & 0.601 & 0.814 & 0.909 & 1.110 & 1.139 & 1.244 & 2.547 & 2.621 & 0.601 \\
\hline SPDI $* * *$ & 15.75 & 16.58 & 17.64 & 17.77 & 17.81 & 17.87 & 18.06 & 18.06 & 18.55 & 18.58 & 21.25 & 21.26 \\
\hline STR*** & 32.34 & 33.30 & 42.41 & 42.41 & 50.26 & 50.26 & 54.98 & 63.45 & 67.39 & 67.44 & 67.63 & 67.70 \\
\hline STB $* * *$ & 7.687 & 7.909 & 7.913 & 7.915 & 8.144 & 9.514 & 10.17 & 13.83 & 14.77 & 18.83 & 22.06 & 22.6 \\
\hline STEQ & 0.740 & 2.574 & 3.926 & 8.022 & 15.22 & 15.76 & 16.07 & 24.77 & 26.67 & 27.55 & 27.80 & 32.66 \\
\hline STIP**** & 11.63 & 16.07 & 16.18 & 16.66 & 16.66 & 17.48 & 18.30 & 18.50 & 19.22 & 21.94 & 25.21 & 25.65 \\
\hline TPR **** & 10.402 & 10.93 & 11.56 & 11.59 & 12.29 & 12.44 & 12.45 & 12.82 & 14.61 & 14.61 & 14.66 & 14.66 \\
\hline TUVES*** & 9.008 & 9.061 & 9.217 & 9.295 & 9.358 & 9.453 & 15.48 & 16.36 & 19.04 & 19.05 & 20.73 & 21.36 \\
\hline TSAR $* * *$ & 18.92 & 21.24 & 30.21 & 32.18 & 32.36 & 32.45 & 33.07 & 33.19 & 34.96 & 35.62 & 35.63 & 36.22 \\
\hline $\mathrm{TL} * * *$ & 71.814 & 71.836 & 72.003 & 72.130 & 72.134 & 75.055 & 75.444 & 75.515 & 76.068 & 76.07 & 76.33 & 76.46 \\
\hline ELB $* * *$ & 6.281 & 6.295 & 7.508 & 7.527 & 7.591 & 9.746 & 9.896 & 10.69 & 11.237 & 11.25 & 11.28 & 11.59 \\
\hline UBCI** & 0.600 & 0.693 & 0.694 & 0.786 & 1.109 & 2.073 & 2.568 & 4.319 & 4.517 & 4.831 & 5.261 & 6.975 \\
\hline UIB $* * *$ & 23.509 & 24.775 & 26.188 & 30.295 & 30.298 & 30.439 & 30.447 & 31.05 & 31.62 & 32.44 & 35.02 & 35.16 \\
\hline$\chi^{2}(\mathrm{q})^{*}$ & 3.841 & 5.991 & 7.815 & 9.488 & 11.070 & 12.592 & 14.067 & 15.507 & 16.919 & 18.307 & 19.675 & 21.026 \\
\hline
\end{tabular}

Depending on the practice if Q-Stat $(\mathrm{q})<\mathrm{X}^{2} 0.05(\mathrm{~K})$, we accept the hypothesis of independence of returns for a risk of 5\%. According to the results set out above, the returns of 13 series studied, presented in bold, are independent. This means accepting the random walk hypothesis. However, the results of the study of the distribution characteristics of our series of profitability have shown that only 12 series do not follow a normal distribution. At this point, the assumption of independence of profitability will be unverified. The remaining 39 series of returns are autocorrelated. In particular, the ARCH effect has been verified for 31 series, since there is at least one step for which Q-Stat (q)> X20.05. This result leads us to conclude that, for these price series, the null hypothesis of the absence of autocorrelation is rejected.

For 30 series, the autocorrelation is of order 1 . For the 9 remaining series the autocorrelation varies from order 2 to 9 . The analysis of the closest to this price series shows that for 5 series we arrive at the absence of autocorrelation from a q equal to 3 . The random walk hypothesis is therefore rejected for these series.

The rational anticipation hypothesis, is not respected for the majority of our profitability series according to which market participants anticipate the future prices of an asset. However, this assumption is based on the relevant information available and not only on past information. The autocorrelation existing in this profitability series may reflect an insufficient transaction volume. This insufficient volume is due to the small size of the Tunisian stock market, whose number of operators is small compared to developed markets, in particular, the presence of foreign investors is almost absent on the Tunisian market. In addition, in practice, the series which presents a random walk is, in general, characterized by more or less high lags. Working with daily data can help explain the linear dependence of the price variations of our series and the existing memory there.

We summarize, the profitability series which verify the random walk, both by the absence of the ARCH effect and the absence of serial correlation, being 10 of the 52 profitability series studied especially, ALKIMIA, AMEN BANK, AMS, BT, ESSOUKNA, MAGASIN GENERAL, MONOPRIX, SOPAT, SOTUVER and UBCI. These results found reject the hypothesis of the efficiency of the Tunisian stock market following these two tests. This confirms 
the results of Biekpe (2007) and Enowbi et al. (2009), which showed the inefficiency of emerging markets in the weak sense.

In conclusion, the Tunisian financial market is based on historical prices at the expense of available information, which can be very useful and relevant. In this case, the prices may not reflect the real value of an asset the value of which depends only on the evolution of past prices. These prices are far from integrating several available information, which can cause a spread between prices and reality.

In fact, the inefficiency of Tunisian stock market is explained by the youth of the latter, which is considered to be narrow, shallow trade and low liquidity. Thus, the low frequency of transactions and the low market capitalization of Tunisian companies compared to those developed markets can cause the inefficiency of the mentioned market.

Our study spanned from 2014 to 2018, a period during which we witnessed tensions following the revolution (December 2010), we can still explain part of irrationality of expectations in Tunisian stock market.

In addition, the lack of transparency from which the Tunisian market suffers. Despite government efforts, it may push investors to consider companies as the primary channels for information transmission. As the role of monitoring organizations is limited, companies can report non-credible and neutral buy or sell recommendations to protect their interests. Followed by investors, these recommendations can affect their decision and information efficiency.

\section{Conclusion}

This paper tests the informational efficiency in the weak form of Tunisian stock market, which supposes that no economic agent can anticipate the future profitably of prices using the sequence of past prices testing the form of efficiency, by the predictive power of past returns on future returns of 52 Tunisian companies listed on the stock market from 2014 to 2018.

The first test of stationarity, showed that all series are stationary. Second, the test of ARCH, aiming at verifying the existence of heteroskedasticity conditional, showed that 34 have an effect type ARCH. Finally, the test of Box Pearce, which has the null hypothesis of correlations serials absence, proved for 39 companies the null hypothesis is rejected. This result proves that the presence of correlations serial in the returns of these companies for which the hypothesis of efficiency in its weak form is rejected. Likewise, the efficiency hypothesis in its weak form is not verified for the majority of samples for the test of ARCH and Box Pearce.

This encourages us to avoid the efficiency in the weak sense in the Tunisian stock market and this results align the previous studies on efficiency of the emerging markets. This inefficiency was explained by the low frequency of transactions, uninformed investors, large price fluctuations, low liquidity, and the strong correlation serial of prices observed. However, the weak form of efficiency theory, through its informative content, is tested in the semi-strong form. Therefore, the analysis of the weak efficiency of the Tunisian market can constitute a starting point for the study of its efficiency in the semi-strong sense.

\section{References}

Al-Khazali, O., et al.. (2007). A new variance ratio test of random walk in emerging markets: A revisit. Financial Review, 40(2), 303-317.

Al-Khazali, O., Zoubi, T., \& Koumanakos, E. (2010). The Saturday effect in emerging stock markets: a stochastic dominance approach. International Journal of Emerging Markets, 5(2), 227-246.

Angelovska, J. (2018). Testing Weak Form of Stock Market Efficiency at the Macedonian Stock Exchange. UTMS. Journal of Economics, 9(2), 133-144.

Assem, S., \& William, J. (1996, June). An empirical investigation of short-selling activity prior to seasoned equity offerings. The Journal of Finance, 51(2), 729-749.

Bollerslev, T. (1986). Generalized Autoregressive Conditional Heteroscedasticity. Journal of Econometrics, 31, 307-327.

Bouattour, M., \& Martinez, I. (2019). Efficient market hypothesis: an experimental study with uncertainty and asymmetric information. Finance Control Strategy, 22-4.

Boussaidi, R. (2016). Causality between daily trading volume and return volatility in the absence of public information: is it over confidence?. Asian Research Journal of Business Management, 4(2), 85-101.

Branes, P. (1986). Thin trading and stock market efficiency: A case of the Kuala Lumpur Stock Exchange. Journal of Business Finance \& Accounting, 13(4), 609-617. 
Carol, A., et al.. (2020). Bitcoin derivatives: Price discovery, informational efficiency, and hedging effectiveness. The Journal of Future Market, 40(1), 23-43.

Chiny, F., \& Mir, A. (2015). Tests de l'efficience du marché financier marocain. Global Journal of Management and Business Research, 1-17.

Chuang, W. I., \& Lee, B. S. (2006). An empirical evaluation of the over confidence hypothesis. Journal of Banking \& Finance, 30, 2489-2515.

Dickey, D. A., \& Fuller, W. A. (1981). Likelihood ratio statistics for autoregressive time series with a unit root. Econometrica, 49, 1057-1072.

Engle, R. F. (1982). Autoregressive conditional heteroscedasticity with estimates of the variance of United Kingdom inflation. Econometrica: Journal of the Econometric Society, 987-1007.

Enowbi, M. B., \& Guidi, F. (2009, August). Testing the weak-form market efficiency and the day of the week effects of some African countries. African Finance Journal.

Enowbi, M. B., \& Mlambo, K. (2009). Linkages between financial development, financial instability, financial liberalization and economic growth in Africa. Research in International Business and Finance, 45, 168-179.

Fama, E. F., \& French, R. K. (1988, October). Dividend yields and expected stock returns. Journal of Financial Economics, 22(1), 3-25.

Fama, E. F., \& French, R. K. (1988, April). Permanent and Temporary Components of Stock Prices. Journal of Political Economy, 96(2), 246-273.

Fama, F. (1970). Efficient Capital Markets: A Review of Theory and Empirical Work. The Journal of Finance, 25(2), 383-417.

Fama, F. (2017). L'efficience informationnelle des marchés financiers. Ouvrage Les Grands Auteurs en Finance, 130-162.

George, T., Kaul, G., \& Nimalendran, M. (1991). Estimation of the bid-ask spread and its components: A new approach. Review of Financial Studies, 4, 622-656.

Huynh, T. D., et. al.. (2017). Stock Price Reaction to News: The Joint Effect of Tone and Attention on Momentum. Journal of Behavioral Finance, 18, 304-328.

Kalu, O. E. (2017). Analysis of sectors on Nigeria stock market: Evidence from correlation, serial correlation, and heteroscedasticity. Journal of Contemporary Economic and Business, 4(2), 21-36.

Khaled, M. (2017). L'efficience informationnelle des marchés financiers. Présentation théorique et validation empirique sur la Bourse d'Alger. Journal of Industrial Economics, 4(13).

Kim, J. H., \& Shamsuddin, A. (2008, June). Are Asian stock markets efficient? Evidence from new multiple variance ratio tests. Journal of Empirical Finance, 15(3), 518-532.

Kryzanowski, L., \& Li, J. (1997). Trading Activity, Quoted Liquidity, and Stock Volatility. Multinational Finance Journal, 1(3), 199-227.

Lee, D. S. (1992). Causal Relations among Stock Returns, Interest Rates, Real Activity, and Inflation. The Journal of Finance, 47(4), 1591-160.

Lo, A. W., \& MacKinlay, A. C. (1988). Stock Market Prices do not Follow Random Walks: Evidence from a Simple Specification Test. The Review of Financial Studies, 1(1), 41-66.

Mlambo, C., \& Biekpe, N. (2007). The efficient market hypothesis: Evidence from ten African stock which are 10 of the 52 profitability series studied markets. Investment Analysts Journal, (66), 5-18.

Neal, R., \& Wheatley, S. M. (1998). Adverse selection and bid-ask spreads: Evidence from closed-end funds. Journal of Financial Markets, 1(1), 121-149.

Nuzzo, S., \& Morone, A. (2017). Asset markets in the Lab: A Literature Review. Journal of Behavioral and Experimental Finance, 13, 42-50.

Omran, M., \& Farrar, S. V. (2006). Tests of weak form efficiency in the Middle East emerging markets. Studies in Economics and Finance, (23), 13-26.

Porter, et al.. (1997). Tick size and market quality. Financial Management, 4(26), 5-26. 
Poterba, J., \& Summers, L. (1986). The Persistence of Volatility and Stock Market Fluctuations. American Economic Review, 76(5), 1142-51.

Saymeh, A., \& Orabi, M. (2013). The Effect of Interest Rate, Inflation Rate, GDP, on Real Economic Growth Rate in Jordan. Asian Economic and Financial Review, 3(3), 341-354.

Sifouh, N., et al.. (2018). Etude Empirique De L'effet Du Comportement D'excès De Confiance Sur La Volatilité Du Marché Boursier Marocain. European Scientific Journal, 14(31).

Stachowiak, C. (2004). Prévisibilité des rentabilités boursières. Une étude empirique du marché boursier français sur données intraquotidiennes. Économie \& prévision, 166, 71-85.

William, G., \& Roger, D. (1995, Jul. - Aug.). Do Individual Returns Herd around the Market. Financial Analysts Journal, 51(4), 31-37.

Worthington, A., \& Higgs, H. (2004). Art as an investment: risk, return and portfolio diversification in major painting markets. Accounting and Finance, 44(2), 257-27.

\section{Notes}

Note 1. M1: Model without constant or temporal drift.

M2: Model with constant or temporal drift.

M3: Model without constant and temporal drift.

Note 2. q: Number of delays in the conditional variance equation which correspond au criteria AIC and Schwarz

$\mathrm{TR}^{2}$ : ARCH Test Statistics

Note 3. *Table de Chi2 5\% threshold 5\%.

$* *$ Serial of the price which the value of Q-Stat $(\mathrm{q})<\mathrm{X}_{0.05, \mathrm{q}}^{2}$

***Serial of the price which the autocorrelation to 1 .

\section{Copyrights}

Copyright for this article is retained by the author(s), with first publication rights granted to the journal.

This is an open-access article distributed under the terms and conditions of the Creative Commons Attribution license (http://creativecommons.org/licenses/by/4.0/). 